\title{
A Code of Conduct for Indonesia: Problems and Perspectives
}

\author{
BY RICCARDO PELIZZO AND BERNICE ANG
}

\begin{abstract}
Previous analyses have shown that the success of ethics reforms such as the adoption of codes of ethics and codes of conduct depends on whether legislators have homogeneous ethical standards. In this paper, we discuss why the DPD (upper chamber) and the DPR (lower chamber) of the Indonesian legislature have decided to enact a code of conduct. The paper also presents the results of a survey that we conducted in the Indonesian legislature. Data analysis reveals that the ethical standards of Indonesian legislators are far from being homogeneous. In the final section of the paper we suggest some of the steps that could be taken to homogenise their ethical views before drafting and implementing the code of conduct.
\end{abstract}

\section{Introduction}

THE purpose of the present paper is fairly straightforward. We want to show that institutional reforms, such as the adoption of codes of conduct, represent a necessary albeit insufficient condition to curb corruption and promote good governance. As several scholars have pointed out, the success of institutional reform, in general, and the success of codes of conduct, in particular, depends, among other things, on ideational conditions. With regard to codes of conduct, parliamentary ethics experts believe that the success of a code of conduct depends in fact upon whether the individuals who are supposed to be regulated by the disposition of the code have a common understanding of what the problems are that the code is supposed to address, or of how the code can solve those problems. In other words, it is argued that the success of codes of conduct for parliamentarians requires homogeneous ethical standards and expectations.

On the basis of a survey conducted among the members of the ethics council of the Indonesian DPD and DPR, we show that values and preferences of Indonesian MPs are far from being homogenous. Hence, we suggest that in order to make codes of conduct successful in Indonesia, it is necessary to homogenise the ethical standards, values and expectations of Indonesian parliamentarians. 
In the course of the paper we proceed as follows. First, we summarise how the institutional approach to the study of politics has evolved over the years. Specifically, we note that in contrast to classical institutionalist arguments, for which political outcomes were somewhat mechanistically determined by institutional arrangements, neo-institutional arguments underline that the relationship between institutions and political outcomes is conditional as it depends on a variety of conditions such as actors' constellation, political will or ideas. Building on this ideational variant of neo-institutionalist arguments, we go on to say that ideational conditions are important for the success of conduct codes. In fact, as the literature has repeatedly observed, the success of codes of conduct depends more on whether MPs have homogeneous values, preferences and expectations than on whether the code establishes severe sanctions.

Secondly, we discuss the Indonesian case. In doing so, we show that in spite of the Indonesian transition to democracy, Indonesia's democracy is characterised by particularly low levels of good governance. On the basis of survey data collected by Transparency International and the World Value Survey, we show that the Indonesian political system is perceived to be very corrupt and that Indonesian citizens have very little trust in Indonesian institutions. We use this evidence to explain why the DPR and the DPD have taken some steps, such as the adoption of an ethics code, and are willing to take some more steps, such as the adoption of codes of conduct, to curb corruption. We conclude this part of the paper by arguing that while enacting ethics reforms is necessary, it may not be sufficient to promote good governance. If ideational institutionalists are correct in saying that the success of conduct codes depends on whether the ethical standards are homogeneous (or not), then we need to know whether this condition is satisfied (or not) in the Indonesian case.

Thirdly, we present the results of a survey conducted among the members of the ethics council of the DPD and the DPR. The data analysis reveals that there is a plurality of ethical standards among Indonesian parliamentarians and this may represent an obstacle for the success of the ethics reforms. In Conclusion Section, we suggest that in order to make ethics reforms succeed in addition to adopting codes of conduct and similar institutional arrangements, it is also necessary to homogenize precisely the ethical standards and expectations of the Indonesian parliamentarians.

\section{Institutionalisms}

Long neglected in political science literature, institutions have received a considerable amount of attention in the course of the past two decades. Rational choice scholars view institutions as those mechanisms that translate individual preferences (micro) into social equilibria 
(macro). ${ }^{1}$ Historical institutionalists believe instead that institutions are not simply mechanisms for translating individual preferences into social equilibria, but believe instead that institutions actually contribute to the formation of individual preferences. ${ }^{2}$ The single most important factor that contributed to the rediscovery of political institutions in general and of constitutions/constitutional mechanisms in particular was the so-called third wave of democratisation. ${ }^{3}$ This wave confronted the political science community with a basic question, namely what institutional/constitutional arrangements are more likely to create the conditions for democratic consolidation? What institutional and constitutional choices should be made to make these newly established democratic regimes survive? In part because constitutions had to be written and institutions had to be set up, in part because without institutions scholars working in the rational tradition did not know how to explain equilibria and in part because institutions were seen as constitutive elements of individual preferences, the past two decades have witnessed a new, and growing interest in the study of political institutions. This has led to a refinement of institutional arguments and analyses and to a pluralisation/proliferation of institutional approaches. Scholars have, for example, recognised that while political outcomes are shaped by political institutions, institutions do not exist and operate in a vacuum. Institutions function in a space which is populated by political actors, who have specific ideas and values. Hence, new generations of studies in the neo-institutional framework have emphasised the importance of actor constellations (Mayntz and Scharpf, 1995) and/or ideas in understanding institutional performance and change. ${ }^{4}$ In the first respect, neo-institutionalists have argued that the impact of institutions on political outcomes is conditional, which means that whether institutional potential of producing a specific outcome is translated into effect or not depends on actor constellations. In the second respect, scholars working in this neo-institutionalist framework have investigated the conditions under which institutional change occurs. In doing so, several scholars have pointed out that the choice of institutions is often the result of an ideational struggle. ${ }^{5}$

Ideas are not only important in explaining how institutions are chosen but also whether and how institutions actually function. The case of ethics reforms is actually a good case in point. Early studies were actually inscribed in classical institutionalist framework, which postulates, somewhat mechanistically, that institutions shape actors behaviour. With regard to the success of ethics reforms and codes of conduct, this classical institutionalist argument suggested that the adoption of conduct codes could contribute to curbing corruption and other forms of misconduct because it established some more or less severe sanctions for violations of the dispositions of the code. 
Hence, in this case, the classical institutionalist argument took the following form:

$$
\text { Conduct code } \rightarrow \text { sanctions } \rightarrow \text { more ethical conduct }
$$

The work by Willa Bruce has shown instead that there is very little evidence supporting this classical institutionalist argument. ${ }^{6}$ First of all, there is very little evidence showing whether the adoption of a conduct code actually leads to more ethical behaviour by the actors that the code is intended to regulate. Bruce showed-and this is our second point-that the adoption of the code is related to lower levels of perceived corruption and misconduct.

Studies on ethics reforms and on the conditions that make ethics reforms successful have provided more support for ideational or cultural institutionalist arguments than for classical institutionalist arguments. Snape and Taylor argued that the ineffectiveness of scrutiny often depends on the fact that there are different and conflicting interpretations of what scrutiny should or should not be. ${ }^{7}$ Morgan stressed that codes of conduct cannot be successfully adopted without paying proper attention to the political culture of the individuals whom the code is supposed to regulate. ${ }^{8}$ Bruce suggested that ethical behaviour is affected by whether individuals are religious/spiritual. ${ }^{9}$ If her argument could be extended to codes of conduct, one could argue that compliance with the dispositions of codes of conduct (and therefore the success of the code itself) is significantly affected by whether the individuals regulated by the code are religious/spiritual. These studies are fairly interesting for our present purposes. In fact, in spite of the fact that the cultural factor is associated with, respectively, interpretation, political culture or religiosity/spirituality, all these studies posit a link between cultural conditions and institutional success (the success of the code in curbing corruption and promoting good governance). This linkage was most forcefully suggested in a study by Skelcher and Snape. ${ }^{10}$ These scholars argued in fact that the success of a conduct code requires the following cultural conditions: (1) the individuals to whom the code is applied must have the same attitudes and values; (2) they must have a shared understanding of what are the problems that the code is supposed to prevent and possibly eliminate; (3) they must have a shared understanding of what the solutions for those problems may be.

If these scholars are correct in positing a linkage between cultural and ideational factors on the one hand institutional success on the other hand, what are the implications for the Indonesian case? This is what we are going to discuss in the remainder of the paper. 


\section{Indonesia and its political context}

After gaining independence in 1949, Indonesia failed to establish a lasting democratic regime. ${ }^{11}$ Although in the early 1950 s there was an initial momentum towards democratic governance, authoritarian dynamics gradually prevailed over the fragile and young Indonesian democracy, so that by the late 1950s Indonesian had become an authoritarian regime under its first President Sukarno. The 'non democratic, New Order regime' was further consolidated under President Suharto in the mid-1960s. Having eliminated former President Sukarno and the Indonesian Communist Party (PKI), Suharto engineered the creation of Golkar, a pro-government political party formed based on bureaucratic and military interests. During his 32 years in power, Suharto created a patrimonial political system that rewarded his supporters, including family and friends, punishing his opponents and the public at large by placing restrictions on civil liberties where elections were held every five years. Indeed, scholars such as MacIntyre $^{12}$ have argued that the government had the authority to vet all political candidates standing for elections, pressuring legislators to be very reluctant in exercising their right to amend or block bills in parliament. Furthermore, keeping in mind the heavy bias towards the executive, military officers were able to occupy up to $20 \%$ of the seats in parliament.

Given all this, it is not surprising that the Freedom House Index labels Indonesia as a 'Partially Free' democratic country for the 19721993 period. ${ }^{13}$ Indonesia was categorised as a 'Non Free' country in the years 1994-1998, when the country was hit by the Asian Financial Crisis. ${ }^{14}$ Indonesia plunged into political and economic turmoil as civil society realised the severity of corruption, collusion and nepotism that were plaguing political institutions. Subsequently, Indonesia recovered its 'Partially Free' status in the $1998-2005$ period. In fact, the quality of democracy in Indonesia has been improving in the post- Suharto era: Indonesia received at 3.5 score on the Gastil Index of Freedom in the 2001-2005 period. This represents a vast improvement in the quality of democracy: from 1974 to 1985, Indonesian democracy (or the lack thereof) never received a score lower than 5 on the Gastil Index of Freedom.

Despite increasing political and economic stability in Indonesia, corruption (as well as other forms of misconduct) remains the most serious problem in post-Suharto Indonesian politics. Research by Transparency International, a leading global coalition against corruption, sustains this claim. Transparency International computes on a yearly basis the 'Corruption Perception Index' (CPI henceforth) which measures the level of corruption perceived in a given country by businessmen and country analysts. ${ }^{15}$ 
The data, presented in Table 1, reveal that Indonesia is consistently perceived to be a very corrupt society. In fact, the CPI for Indonesia has never been higher than 3. A simple comparison allows us to understand what it means having such a low score. Regardless of the number of countries being sampled worldwide, Indonesia has always ranked among the most corrupt societies in the world. Of course, one should keep in mind that the CPI estimated by Transparency International does not really measure objective corruption, it provides an indication of how much corruption is perceived to exist in a country and as such they do not provide the best possible ground for making cross-country comparisons. Yet, these data all point in the same direction, namely that Indonesia is perceived to be very corrupt, that corruption represents a major problem in Indonesian politics in and by itself and that corruption may be problematic as it is associated with falling levels of trust. ${ }^{16}$ In sum, corruption is perceived to be a serious problem in Indonesia and this is why it is so important to take some steps to curb and possibly eliminate corruption (along with other forms of misconduct).

Transparency International developed another important tool (the Corruption Barometer) to assess the severity of corruption within institutions and its impact on the level of trust citizens have in these institutions. ${ }^{17}$ The list of institutions includes parliaments, political parties, the military and judiciary. In 36 countries out of 62 surveyed, political parties were rated by the general public as the institution most affected by corruption; but Indonesia's civil society sentiments differed from these findings (see Table 2).

According to the Corruption Barometer 2004, respondents in Indonesia rated their parliaments and legislatures to be the most corrupt institutions (along with, of course, political parties).

Given the high level of perceived corruption, Indonesian institutions enjoy low levels of trust. The fourth wave of the World Values Survey

1. Indonesia's CPI Performance (in 10 years)

$\begin{array}{llllc}\text { Year } & \text { Corruption index } & \text { Individual rank } & \text { Total no of countries } & \text { Percentile } \\ 2005 & 2.20 & 137 & 159 & 86.16 \\ 2004 & 2.00 & 133 & 146 & 91.10 \\ 2003 & 1.90 & 122 & 133 & 91.73 \\ 2002 & 1.90 & 96 & 102 & 94.12 \\ 2001 & 1.90 & 88 & 91 & 96.70 \\ 2000 & 1.70 & 85 & 90 & 94.44 \\ 1999 & 1.70 & 96 & 99 & 96.97 \\ 1998 & 2.00 & 80 & 52 & 94.12 \\ 1997 & 2.70 & 46 & 54 & 88.46 \\ 1996 & 2.65 & 45 & 41 & 83.33 \\ 1995 & 1.94 & 41 & \end{array}$

Source: Transparency International, 1995-2005. 
2. To what extent do you perceive this institution to be affected by corruption?

Institutions

Political parties

Parliament/legislature

Legal system/judiciary

Police

Business/private sector

Tax revenue

Customs

Media

Medical services

Education system

Registry and permit services

Utilities

Military

NGOs

Religious bodies
Perception of corruption

4.4

4.4

4.2

4.2

3.7

4

4.3

2.6

3

3.2

3.7

3.1

3.3

2.4

1.8

Source: Transparency International, 1995-2005. Note: scale 1 (not at all corrupt) to 5 (extremely corrupt).

conducted in 1998-2001 revealed that Indonesians generally have very little confidence in any type of national institution. Data are presented in Table $3 .{ }^{18}$

About a thousand respondents were interviewed in Indonesia by the World Value Survey. Respondents were asked to express on a 4 point scale-from 1 (great deal of confidence) to 4 (none at all)-how much confidence they had in 15 private, public and regional institutions. Since Indonesia was slowly recovering from the Asian Financial Crisis and was struggling to consolidate its new form of 'democracy' after the Suharto years in 2001, it comes as no surprise that the Indonesian respondents were still wary of such large institutions that were still regarded as both inefficient and corrupt. To sum up, what we have said so far suggests three basic conclusions, namely that:

(1) Indonesia has consistently been perceived to be highly corrupt and to be one of the most corrupt countries in the world;

(2) The parliament (along with parties) is perceived to be the most corrupt institution in Indonesia;

(3) The Parliament is one of the three least trusted institutions in Indonesia.

One solution to regain citizens' trust consists in enacting ethics reforms and creating ethics regime. This means that a political system which is (or is at least perceived to be) corrupt implements some institutional reforms to reduce corruption and regain the trust of the citizens. This is why ethics reforms and the creation of ethics regimes are said to perform both an internal as well as an external function. ${ }^{19}$ 
3. World Values Survey: Indonesia's level of confidence in different institutions and organisations

$\begin{array}{lcccc}\text { Organisation/institution } & \text { A great deal } & \text { Quite } \text { lot } & \text { Not very much } & \text { Not at } \\ \text { Churches } & 75 & 21.7 & 2.8 & 0.4 \\ \text { Armed forces } & 16.6 & 57.3 & 24.1 & 1.9 \\ \text { The Press } & 5.8 & 49.1 & 42.7 & 2.4 \\ \text { Labour unions } & 4.5 & 33.4 & 55.3 & 6.8 \\ \text { The police } & 9 & 43 & 43.4 & 4.6 \\ \text { Parliament } & 3.2 & 39.8 & 49.6 & 7.4 \\ \text { The civil services } & 8.5 & 50.9 & 36.9 & 3.7 \\ \text { Television } & 9.1 & 52.2 & 36.8 & 1.9 \\ \text { The Government } & 9.4 & 43 & 42.9 & 4.8 \\ \text { The political parties } & 3.9 & 29.2 & 57 & 9.9 \\ \text { Major companies } & 6.3 & 40.7 & 47.2 & 5.9 \\ \text { The environmental protection movement } & 9.9 & 44.9 & 40.4 & 4.7 \\ \text { The women's movement } & 6.8 & 43.9 & 42.6 & 6.8 \\ \text { UN } & 10.3 & 37.7 & 40.7 & 11.3 \\ \text { ASEAN } & 9 & 44 & 39.6 & 7.3\end{array}$

Source: World Values Survey, 1981-2004 (Country: Indonesia, 2001).

Note: Rank Scale (1: a great deal, 4: not at all).

The creation of ethics regimes, as discussed in the scholarly literature, can occur by either adopting ethics codes or adopting conduct codes. ${ }^{20}$ Ethics codes state what are the main ethical values and principles of an organisation, but they have no bite. In contrast, conduct codes are remarkably more specific. They clearly indicate which forms of conduct represents an acceptable conduct and which types of conduct are to be regarded as improper. Moreover, codes of conduct differ from ethics codes in a second respect: codes of conduct establish sanctions for punishing violations of the provisions of the code.

Given the persistently high levels of perceived corruption and the low levels of public trust in political institutions, the Indonesian legislature was forced to take some steps in order to curb corruption, to show its commitment to the principles and the values of good governance and to regain the trust of its citizens. The Indonesian parliament tried to do so by enacting some ethics reforms. The DPR (lower house) adopted a code of ethics on 29 September, 2004 and it is considering whether and to what extent it would be advisable to couple the adoption of the ethics code with the adoption of a conduct code. The DPD has already taken a more entrepreneurial approach with regard to the adoption of a conduct code. In fact, in spite of the fact that the ethics council of the DPD does not have the constitutional mandate to draft legislation, it has already prepared a draft of a code of conduct to manifest its commitment to ethics reforms and good governance.

While the steps taken by the ethics council of the DPD and the DPR are encouraging as they show these institutions' commitment to adopting a code of conduct, improving governance and fighting corruption, 
it is worth keeping in mind that the process of institutional reform is not an easy one. In discussing which dispositions should be included in the code of conduct, the members of the ethics council of both the DPD and the DPR have manifested some skepticism as to the adoption of rules forcing members to either disclose or register their interests. In addition to this one should note that the members of the ethics council of DPD who are mostly businesspeople or entrepreneurs of some sort, strongly oppose the adoption of regulations that may force them to give up their job in the private sector while they serve their term in office. $^{21}$ Personal conversations between one of the authors of this paper and the members of ethics council in the DPR and the DPD revealed that while members are in favour of adopting the code, they may oppose the adoption of gifts and travel restrictions that are key component of any code of conduct. Hence, we believe that the adoption of a code of conduct is confronted with the following conundrum: if the dispositions of the code are too stringent (no gift, disclosure of interests, job restrictions), members may oppose the adoption of such a code; conversely if the dispositions of the code have no bite, regardless of how much support they may receive from MPs, they will not be able to significantly affect the ethical behaviour of Indonesian legislators.

Be that as it may, given the interest demonstrated both by the members of the DPD and by the DPR in institutional reforms, ethics regimes and codes of conduct, we administered a survey to the members of the ethics council of the DPD and the DPR. We conducted this survey to assess whether and to what extent Indonesian MPs have homogeneous ethical standards-which is what is required to make conduct codes succeed-or not. The results of our survey will be presented and discussed in the next part of the paper.

\section{Perceptions of corruption survey}

In order to examine sentiments towards corruption of the members of the DPD and the DPR, we conducted a survey on 'General Sentiments on Corruption'. ${ }^{22}$ In this survey we used a questionnaire that had originally been devised by Mancuso to investigate the ethical world of British MPs. ${ }^{23}$ Mancuso, in addition to asking general questions on corruption, asked a sample of 100 British MPs to indicate on a 7 point scale how corrupt they considered certain activities. Value 1 on the scale meant that for a given MP a specific action was very corrupt, whereas value 7 indicated instead that that action was considered to be not corrupt at all. ${ }^{24}$

We decided to use this questionnaire for two reasons. The first reason is that we believe that such a questionnaire allows the analyst to gain some insight into the ethical values and preferences of parliamentarians. The second reason is that by adopting Mancuso's questionnaire, we are able to generate data that may be used for cross-country comparisons which, we believe, may help shed some light into the 
ethical standards of parliamentarians and into how these standards may determine the success or the failure of ethics reforms.

Be that as it may, in this part of the survey (six questions), respondents were required to indicate their level of agreement or disagreement to each of the six statements, ranging on a 7 point scale from 1 (Strongly agree) to 7 (strongly disagree).

Indonesian parliamentarians believe that corruption can be eliminated, that is more widespread at the national than at the local level, that politicians are more corrupt than business people, that corruption reflects a society's ethical standards and that corruption is indeed a major problem in Indonesia. Given these answers, one could note that if corruption is a problem that can be solved and if corruption reflects a society's standards, then political elites in Indonesia in addition to implementing ethics reforms should also take some steps to educate the public and to modify/improve society's ethical preferences and values. But we need to make a second and more important remark, namely that the data analysis reveals that the ethical standards among the member of the ethics council in the DPD and in the DPR are not homogenous. Most of the respondents view political corruption as a widespread problem and agree dishonesty is more common in politics than in business, but the agreement on these issues is far from being unanimous.

The answers, as we mentioned earlier on in the paper, are given on a 7 -point scale. Value 1 indicates strong agreement, value 7 indicates strong disagreement and value 4 indicates that a respondent is neutral about a given issue. To assess how much disagreement there is on the six issues on which respondents were asked to express their views, we proceed as follows. We discount all the answers in the neutral category, we add up all the answers indicating agreement (however strong) and we add all the answers indicating disagreement (however strong). By doing so, we find that there is some disagreement on most issues and that on some issues disagreement is quite pervasive.

About $55 \%$ of the respondents agree that political corruption is widespread, but more than $22 \%$ of them disagree with that view. About $44 \%$ of the respondents agree that the reason why voters do not trust politicians is that they do not understand politics, but this view is opposed by $37 \%$ of the respondents. In other words, members of the ethics council in the DPD and in the DPR are almost evenly split on this issue. About $65 \%$ of the respondents agree that dishonesty is more widespread in politics than in business, but $18 \%$ of them actually disagrees. About $70 \%$ of the respondents regard hiring the wife or a relative as personal secretary as a corrupt action, while this behaviour is regarded as perfectly legitimate by $20 \%$ of the respondents. ${ }^{25}$

For more than $50 \%$ of the respondents, corruption is more common at the national level, whereas almost $15 \%$ of the respondents holds the opposite view. Opinions differ also as to whether corruption can 
be eliminated. In fact, while $55.5 \%$ of the respondents believe that corruption can be eliminated, about $26 \%$ of the respondents hold the opposite view.

To examine further the opinions of the respondents, we calculated the degree of polarisation possibly arising towards these six statements. Building upon the work of Sartori, Pelizzo and Babones constructed the Pelizzo-Babones index of polarisation. ${ }^{26}$ According to Sartori 'we have polarization when we have ideological distance (in contrast to ideological proximity). ${ }^{27}$ This notion, developed by Sartori to analyse party systems, meant that a party system is (highly) polarised when the parties located at the extreme ends of the political spectrum are 'twopoles apart' and 'the distance between them covers a maxim spread of opinion'. ${ }^{28}$ Sartori, however, did not specify in his work on party systems, how polarisation should be best estimated. Taylor and Herman proposed two ways of estimating polarisation, one of which is to measure the standard deviation of the distribution of seats across parties. $^{29}$ Standard deviation can also be applied to survey data. Whenever voters are asked to place themselves on a 7 point scale or to say how conservative-liberal they are, the standard deviation provides a good indication of the total spread of opinion. The advantage of the Pelizzo-Babones index over the standard deviation to measure polarisation is that is more intuitive. ${ }^{30}$ They defined polarisation as the total spread of opinion suggested that polarisation can be measured by the following formula:

(extreme left + extreme right $)-$ centre.

This definition of polarisation can be used to assess the amount of disagreement on ethics issue within the Indonesian council of ethics. The Pelizzo-Babones index of polarisation can be used in this paper by adding the percentage of the responses located at the two extremes of the scale and by subtracting the number of neutral responses from the total of extreme responses, that is:

$$
\{\text { strongly agree }+ \text { strongly disagree }\}-\text { neutral }
$$

By applying this simple formula to the data presented in Table 4, we are able to establish the polarisation of respondents' views towards general statements of corruption as shown in Table 5. From these computations, we find that polarisation of views among parliamentarians ranges from 11 to $37 \%$ for only five issues. The fourth scenario stating that 'corruption is more widespread at local than national level' was proved to be one of the least contentious issues among respondents regarding this survey, with a score of $-3.7 \%$ on the polarisation index. The highest level of polarisation, and, therefore, the greatest 
4. General statements on corruption

Political corruption a widespread problem

People do not trust politicians as they do not understand politics

Dishonesty more widespread in politics than in business

Corruption more widespread at local than national level

No matter what we do, corruption can never be eliminated

Corruption reflects standard of society

\begin{tabular}{ccccccccc}
$\begin{array}{l}\text { Strongly } \\
\text { agree }\end{array}$ & \multicolumn{3}{c}{ Neutral } & & \multicolumn{3}{c}{$\begin{array}{c}\text { Strongly } \\
\text { disagree }\end{array}$} & Mean \\
1 & 2 & 3 & 4 & 5 & 6 & 7 & \\
40.7 & 7.4 & 7.4 & 22.2 & 7.4 & 7.4 & 7.4 & 3 \\
14.8 & 0.0 & 29.6 & 18.5 & 22.2 & 0.0 & 14.8 & 3.93 \\
40.7 & 14.8 & 11.1 & 14.8 & 7.4 & 7.4 & 3.7 & 2.7 \\
14.8 & 0.0 & 0.0 & 33.3 & 14.8 & 22.2 & 14.8 & 4.59 \\
18.5 & 0.0 & 7.4 & 18.5 & 0.0 & 18.5 & 37 & 4.85 \\
& & & & & & & \\
29.6 & 18.5 & 14.8 & 18.5 & 0.0 & 3.7 & 14.8 & 3.11
\end{tabular}

amount of disagreement, was recorded on whether corruption can or cannot be eliminated. The second most contentious item was whether dishonesty is more common in politics or in business. Respondents were equally polarised as to whether political corruption is a widespread phenomenon and as to whether corruption reflects the ethical standards of a society. The polarisation in each of these four scenarios was higher than $25 \%$. These results suggest that the ethical attitudes and perspectives of Indonesian parliamentarians are far from homogeneous. Without a homogeneous set of ethical perspectives and values, it is very difficult to make codes of conduct succeed in the long term. In order to ensure such success, the ethical standards of Indonesian parliamentarians must be homogenised, reducing possible polarisation of opinions on ethical issues.

\section{Polarization of views on General Statements of Corruption}

\begin{tabular}{|c|c|c|c|c|}
\hline & $\begin{array}{l}\text { Strongly } \\
\text { agree, } 1\end{array}$ & $\begin{array}{l}\text { Neutral, } \\
4\end{array}$ & $\begin{array}{l}\text { Strongly } \\
\text { disagree, } 7\end{array}$ & $\begin{array}{l}\text { Polarization, } \\
{[1+7]-4}\end{array}$ \\
\hline Political corruption a widespread problem & 40.7 & 22.2 & 7.4 & 25.9 \\
\hline $\begin{array}{l}\text { People do not trust politicians as they do } \\
\text { not understand politics }\end{array}$ & 14.8 & 18.5 & 14.8 & 11.1 \\
\hline $\begin{array}{l}\text { Dishonesty more widespread in politics } \\
\text { than in business }\end{array}$ & 40.7 & 14.8 & 3.7 & 29.6 \\
\hline $\begin{array}{l}\text { Corruption more widespread at local than } \\
\text { national level }\end{array}$ & 14.8 & 33.3 & 14.8 & -3.7 \\
\hline $\begin{array}{l}\text { No matter what we do, corruption can } \\
\text { never be eliminated }\end{array}$ & 18.5 & 18.5 & 37 & 37 \\
\hline Corruption reflects standard of society & 29.6 & 18.5 & 14.8 & 25.9 \\
\hline
\end{tabular}


In order to assess properly how homogeneous were the ethical standards of the Indonesian MPs, respondents were also provided with ten corruption scenarios and were asked to rank each of these scenarios on a 7-point scale where 1 meant corrupt and 7 meant non-corrupt.

Data analysis reveals that eight of the ten scenarios were considered as corrupt scenarios by the respondents, who however regarded accepting cigars from wealthy constituents and arranging meetings between MPs and businessmen as non-corrupt practices.

The data analysis also reveals that there is a quite a bit of disagreement among MPs as to how various activities should be judged. For example, while about $40 \%$ of the respondents regarded arranging meeting between MPs and businessmen as corrupt, about $44 \%$ of the respondents considered this practice as non-corrupt. Accepting cigars were viewed as a corrupt behaviour by about $25 \%$ of the respondents, whereas it was treated as non-corrupt by $44 \%$ of the respondents. Yet, these scenarios are not clear cut cases of corruption. What is truly surprising is the fact that for some MPs promising appointments in exchange for campaign contributions, using influence to get a friend a job, awarding a contract to a company which had made a major campaign contribution are not unanimously viewed as corrupt practices. For $16 \%$ of the respondents promising an appointment position in exchange of campaign contribution did not represent a clear cut case of corruption. For $15 \%$ of the respondents using influence to get a friend a job does not represent a corrupt behaviour. Even more surprisingly, 3.7 of the respondents did not regard awarding a public contract to a company that had made major donations to party finance as a corrupt action.

Once again, by applying the Pelizzo-Babones index of polarisation to the data presented in Table 6, we are able to analyse the polarisation of Indonesian parliamentarians' responses towards various corruption scenarios. On close analysis of the computations reflected in Table 7, the spectrum of polarisation ranges from a minimum of about $7 \%$ to a maximum of about $74 \%$. Indeed, the wide range of parliamentarians' perceptions and opinions towards these scenarios shows, alarmingly, the lack of general consensus among Indonesian MPs on ethical issues. This analysis, coupled with our findings presented in Table 5, sustains the claim that Indonesian MPs have a multiplicity of ethical standards. If Snape and Skelcher are correct in saying that the success of codes of conduct depends, among other reasons, on whether there are homogeneous ethical standards, that MPs agree on what the problems are that the code should solve, and on what dispositions should be put in the code to address those problems, the data that we have presented clearly indicate that these conditions are not met in the Indonesian case. Does this evidence leads to inevitable conclusion that there is no hope for implementing ethics reforms in Indonesia? Or is 
6. Corruption scenarios

\begin{tabular}{|c|c|c|c|c|c|c|c|c|}
\hline & Very & & & Neut & & & No corrupt & Mean \\
\hline & 1 & 2 & 3 & 4 & 5 & 6 & 7 & \\
\hline $\begin{array}{l}\text { Cabinet minister } \\
\text { promises } \\
\text { appointment position } \\
\text { exchange for } \\
\text { campaign } \\
\text { contribution }\end{array}$ & 42.3 & 11.5 & 30.8 & 7.7 & 0.0 & 3.8 & 3.8 & 2.38 \\
\hline $\begin{array}{l}\text { MP using influence to } \\
\text { get friend/relative } \\
\text { admitted to } \\
\text { prestigious institution }\end{array}$ & 40.7 & 22.2 & 18.5 & 11.1 & 3.7 & 3.7 & 0.0 & 2.26 \\
\hline $\begin{array}{l}\text { MP using influence to } \\
\text { get friend/relative a } \\
\text { job }\end{array}$ & 33.3 & 22.2 & 29.6 & 3.7 & 3.7 & 3.7 & 3.7 & 2.48 \\
\hline $\begin{array}{l}\text { Cabinet minister use } \\
\text { influence to obtain } \\
\text { contract for firm in } \\
\text { his constituency }\end{array}$ & 44.4 & 18.5 & 14.8 & 11.1 & 3.7 & 3.7 & 3.7 & 2.37 \\
\hline $\begin{array}{l}\text { MP arrange for } \\
\text { meetings between } \\
\text { private corporation } \\
\text { executives and } \\
\text { parliamentarians }\end{array}$ & 11.1 & 11.1 & 18.5 & 14.8 & 0.0 & 11.1 & 33.3 & 4.48 \\
\hline $\begin{array}{l}\text { MP hires wife or family } \\
\text { member to serve as } \\
\text { his secretary }\end{array}$ & 40.7 & 22.2 & 7.4 & 7.4 & 11.1 & 0.0 & 11.1 & 2.7 \\
\hline $\begin{array}{l}\text { MP accepts a box of } \\
\text { cigars from } \\
\text { influential constituent }\end{array}$ & 7.4 & 11.1 & 7.4 & 29.6 & 3.7 & 11.1 & 29.6 & 4.63 \\
\hline $\begin{array}{l}\text { Major company makes } \\
\text { big donation to } \\
\text { government party, } \\
\text { eventually won major } \\
\text { contract }\end{array}$ & 70.4 & 22.2 & 3.7 & 0.0 & 0.0 & 0.0 & 3.7 & 1.52 \\
\hline $\begin{array}{l}\text { MP exchange 1st class } \\
\text { ticket allocated for } \\
\text { economy class, } \\
\text { pockets the difference }\end{array}$ & 42.3 & 15.4 & 7.7 & 15.4 & 7.7 & 0.0 & 11.5 & 2.77 \\
\hline $\begin{array}{l}\text { MP gets house pass for } \\
\text { lobbyist to act as } \\
\text { research assistant } \\
\text { whose services paid } \\
\text { for by external source }\end{array}$ & 44 & 24 & 4 & 20 & 4 & 4 & 0.0 & 2.28 \\
\hline
\end{tabular}

there some way in which the process of institutional reforms can be secured?

\section{Achieving homogeneity in ethical standards}

Our argument that heterogeneous ethical standards may represent an obstacle for ethics reforms is consistent with the work developed 
7. Polarisation of views on corruption scenarios

Very corrupt, 1 Neutral, $4 \quad$ Not corrupt, 7

\begin{tabular}{|c|c|c|c|c|}
\hline $\begin{array}{l}\text { Cabinet minister promises } \\
\text { appointment position } \\
\text { exchange for campaign } \\
\text { contribution }\end{array}$ & 42.3 & 7.7 & 3.8 & 38.4 \\
\hline $\begin{array}{l}\text { MP using influence to get } \\
\text { friend/relative admitted } \\
\text { to prestigious institution }\end{array}$ & 40.7 & 11.1 & 0.0 & 29.6 \\
\hline $\begin{array}{l}\text { MP using influence to get } \\
\text { friend/relative a job }\end{array}$ & 33.3 & 3.7 & 3.7 & 33.3 \\
\hline $\begin{array}{l}\text { Cabinet minister use } \\
\text { influence to obtain } \\
\text { contract for firm in his } \\
\text { constituency }\end{array}$ & 44.4 & 11.1 & 3.7 & 37 \\
\hline $\begin{array}{l}\text { MP arrange for meetings } \\
\text { between private } \\
\text { corporation executives } \\
\text { and parliamentarians }\end{array}$ & 11.1 & 14.8 & 33.3 & 29.6 \\
\hline $\begin{array}{l}\text { MP hires wife or family } \\
\text { member to serve as his } \\
\text { secretary }\end{array}$ & 40.7 & 7.4 & 11.1 & 44.4 \\
\hline $\begin{array}{l}\text { MP accepts a box of cigars } \\
\text { from influential } \\
\text { constituent }\end{array}$ & 7.4 & 29.6 & 29.6 & 7.4 \\
\hline $\begin{array}{l}\text { Major company makes big } \\
\text { donation to government } \\
\text { party, eventually won } \\
\text { major contract }\end{array}$ & 70.4 & 0.0 & 3.7 & 74.1 \\
\hline $\begin{array}{l}\text { MP exchange first class } \\
\text { ticket allocated for } \\
\text { economy class, pockets } \\
\text { the difference }\end{array}$ & 42.3 & 15.4 & 11.5 & 38.4 \\
\hline $\begin{array}{l}\text { MP gets house pass for } \\
\text { lobbyist to act as } \\
\text { research assistant whose } \\
\text { services paid for by } \\
\text { external source }\end{array}$ & 44 & 20 & 0.0 & 24 \\
\hline
\end{tabular}

Polarisation, $[1+7]-4$

within the cultural group theory. ${ }^{31}$ Building on Wildavski-Douglas's group-grid, where 'grid' indicates the extent to which individual preferences or actions are affected by her position in society and where 'group' indicates the level of solidarity in the social group, cultural theorists have created a four-fold typology: hierarchist (high-grid and high-group scores), egalitarian (low-grid score, high-group score), individualist (low-grid and low-group scores) and fatalist (high-grid, lowgroup scores). ${ }^{32}$ These four types are seen as a way of organising or of risk perception. ${ }^{33}$

Cultural theory posits that problems in policy-making, from the implementation of suboptimal policies to the preservation of the 
(suboptimal) status quo, stem from the fact that some of these positions are neglected in policy debates. To avoid these shortcoming, cultural theorists have advocated the adoption of one of the following two approaches. Some scholars have advocated the democratisation of policy debates so that each of the four perspectives can be taken into proper consideration and that agreements between individuals belonging to the four ways of life can be achieved on different levels. ${ }^{34}$ Other cultural theorists have investigated instead how preferences can be homogenised without eliminating the plurality of cultural perspectives. The solution in this respect is represented by making policy options compatible with the value of each of the four groups. This result can be achieved in three steps. ${ }^{35}$ First, policy proposals should be 'expressively overdetermined', which means that they should be 'sufficiently rich in social meanings that individuals of otherwise opposing cultural orientations (...) can see their way of life affirmed by it'. Secondly, leaders within each cultural group should 'be recruited to advocate expressively overdetermined policies' because group members are more likely to be persuaded by high-profile members of their groups. ${ }^{36}$ Thirdly, group members should be persuaded that the outcome of the policy debate should not be regarded as the success of a group over the others or as an indication of the balance of power among the four groups.

While this approach has generally been adopted to discuss policy issues such as gun control, abortion, global climate change, it provides some clear indications as to what could be done Indonesia to adopt, implement and successfully administer a legislative code of conduct. First of all, it is important to frame ethics reforms and the adoption/ implementation of a code of conduct in the wider context of promoting governance and development. While MPs may be individually opposed to codes of conduct per se, Indonesian MPs are aware of the importance of promoting socio-economic development in a country that has not been as successful as its neighbors in the region. Leaving Singapore aside, both Malaysia and Thailand have become more developed and economically successful than Indonesia. Hence, by framing the adoption of the code of conduct as a key part of a wider strategy to promote good governance and, through governance, development, institutional reformers can create a consensus on adopting and administering a code of conduct. Secondly, party leaders and committee chairs, who are trusted respectively by their fellow party members and committee members, should play an active role in advocating the adoption/administration of a code of conduct. Third and finally, institutional reforms should make clear to their fellow MPs that the adoption of ethics reforms such as codes of conduct is not the success of any specific group, but is beneficial for the parliament as a whole for two reasons. By adopting and implementing a code of conduct, the parliament would signal its commitment to transparency in 
government and possibly regain the citizen trust, without which democratic institutions struggle to survive. As Lipset pointed out in his seminal work, while democracies need socio-economic development and performance to survive, they need legitimacy above else. ${ }^{37}$ That is, they to preserve the belief that democratic government and institutions are the best for the country. Moreover, by adopting ethics reforms, reducing corruption, promoting good governance and thus contributing to the country's socio-economic development, the parliament takes an important step to improve the performance of the political system and, by doing so, to consolidate the legitimacy of the democratic regime itself. And since the political careers of individual MPs, regardless of their partisan affiliation, depend on the survival of democracy, adopting and implementing a code of conduct represents for all MPs a way of securing their individual interests and career ambitions.

\section{Conclusions}

Scholars working within the ideational or cultural institutionalist framework have argued that the conditions for the successful adoption and administration of codes of conduct are represented by a homogeneity of ethical standards of the individuals that the code is expected to regulate. The evidence presented in this paper suggests that this condition is not met in the Indonesian case and, therefore, it may be difficult to adopt and, more importantly, effectively administer a code of conduct in the Indonesian parliament.

The obvious limitation of our argument is that it postulates homogeneity of ethical standards as a prerequisite for successfully implementing ethics reforms. Yet, one could very well argue that by adopting and enforcing a properly crafted code of conduct and by clarifying the meaning of the dispositions of the code (thus detailing which forms of behaviour are acceptable and which are not), the code may contribute to the homogenisation of ethical standards and create the conditions of its own success. Such an observation is obviously well taken, and there is no reason to doubt that the relationship between codes of conduct and the homogeneity of ethical standards is bi-directional and not, as we have assumed in the paper, unidirectional. If this were the case, one could conclude that the success of political institutions depends on proper institutional design and on the fact that particular institutional arrangements, in our case the codes of conduct, need to be embedded in a wider, more articulated institutional context. This means that legislatures need not only to have a code, but that they also need to establish ethics committees to administer such codes and clarify the meaning of their dispositions. Unfortunately, the evidence at our disposal does not allow us to say whether and to what extent the adoption of a code makes ethical standards more homogeneous. 
In the paper, however, we discuss some ways in which the views of Indonesian MPs can be depolarised and made more homogeneous. Building on the work of cultural theorists, we discuss some ways in which consensus on various scenarios and more generally on the adoption of a code of conduct can be reached. Specifically, we argued that if ethics reforms and the adoption of a code of conduct are discussed in a way that is compatible with the values of individuals that the code is supposed to regulate; if institutional reformers make clear that the adoption of a code of conduct does not amount to a zero sum game, and if political leaders play an active role in bringing this message across, individuals can converge in their belief about acceptable behaviour and on the necessity of adopting a code.

1 G. Tsebelis, Veto Players, Princeton UP, 2002.

2 S. Steinmo, K. Thelen and F. Longstreth (eds), Structuring Politics: Historical Institutionalism in Comparative Analysis, Cambridge UP, 1992.

3 S. Huntington, The Third Wave of Democratization, University of Oklahoma Press, 1991.

4 R. Mayntz and F.W. Sharpf, 'Der Ansatz des akteurzentrierten Institutionalismus', in R. Mayntz and F. W. Scharpf (eds), Gesellschaftliche Selbstregelung und politische Stenerung (= Schriften des Max-Planck-Instituts für Gesellschaftsforschung Köln. 23), Campus, 1995, pp. 39-72.

5 M. Blyth, Great Transformations, Cambrdige UP, 2002.

6 W. Bruce, 'Codes of Ethics and Codes of Conduct: Perceived Contribution to the Practice of Ethics in Local Government', Public Integrity Annual, 1996, 23-29.

7 S. Snape and F. Taylor, 'A hard nut to crack? Making Overview and Scrutiny Work', Working Paper, Local Government Association, 2001.

8 M. Morgan, 'State Society and Governance in Melanesia', Discussion Paper n. 2, Australian National University, Research School of Pacific and Asian Studies, 2005.

9 W. Bruce, Bruce, Willa M. 'Public Administrator Attitudes About Spirituality', American Review of Public Administration, 30, (4), 2000, pp. 414-435.

10 C. Skelcher and S. Snape, 'Ethics and Local Councilors: Modernising Standards of Conduct', Parliamentary Affairs, 54, (1), 2001, pp. 72-78.

11 The Indonesian case is not exceptional in this regard. Many of the countries that democratised in the course of the second wave of democratisation were unable to consolidate democracy, suffered democratic breakdowns contributing to what Huntington defined as 'second reverse wave'.

12 Andrew MacIntyre, Investment Property Rights and Corruption in Indonesia, Ateneo University Press, 2001. [http://apseg.anu.edu.au/pdf/macintyre_papers/Investme.pdf].

13 The Freedom House or Gastil index is estimated on a yearly basis by Freedom House. The data can be found at the following webpage: http://www.freedomhouse.org/uploads/fiw/FIWAllScores.xls.

14 Freedom House computes an annual index of freedom for all the countries in the world. This index is computed in the following way. The Freedom House assigns to each country a political rights and a civil rights score. Both scores are 7-point scales. The Gastil index is measured by adding the political rights score to the civil rights score and by dividing their sum by two. This means that if a country has a political rights score of 3 and a civil rights score of 4 , the freedom score for this country is $(3+$ $4) / 2=3.5$. Countries that score from 1 to 2.5 points on this scale are considered free; countries scoring from 3 to 5.5 are considered as partially free and countries with a score of 5.5 or higher belong to the group of non-free countries.

15 The CPI is measured on a 10-point scale between where 0 indicates highly corrupt and where 10 indicates instead highly clean, see [http://ww1.transparency.org/].

16 We will elaborate this point in greater detail later on in the paper.

17 Respondents were asked to rank on a 5-point scale the extent to which they perceived various institutional sectors to be affected by corruption.

18 World Values Survey contains the work of social scientists worldwide who desire to produce evidence that there are gradual but pervasive changes occurring in each country's society that its citizens want out of life. There have been four waves of survey analysis, and Indonesia was only sampled on the fourth wave in 2001. [http://www.worldvaluessurvey.org/organization/index.html]. 
19 R. Pelizzo and R. Stapenhurst, 'Legislative Ethics and Codes of Conduct', in R. Stapenhurst, N. Johnston and R. Pelizzo (eds), The Role of Parliaments in Curbing Corruption, The World Bank, 2006, pp. 195-203.

20 G. Pasquino and R. Pelizzo, Parlamenti Democratici, il Mulino, 2006, Ch. 6.

21 In this respect, Sherlock noted that 'DPD Members are elected as individuals and are not permitted to be sponsored by political parties. Despite concerns that political parties would attempt to take over and control the DPD through indirect means, it appears that there has not been any major organised forays into the assembly by the parties'. The quote is taken from S. Sherlock, 'Indonesia's Regional Representative Assembly', Centre for Democratic Institutions, 2006, p. 2. The insight on the professional background of DPD members was provided by Indraneel Datta from IDEA.

22 The survey of the member of the ethics council of the DPR was administered in the course of a workshop on parliamentary ethics and codes of conduct organised by the National Democratic Institute. The survey was administered to the members of the ethics council of the DPD by Indraneel Datta of IDEA. We wish to thank IDEA, NDI, Indraneel Datta and Tom Cormier for all their help and support. We wish to thank Rick Stapenhurst who made all this possible.

23 M. Mancuso, 'Ethical attitudes of British MPs', Parliamentary Affairs, 46, (2), 1993, 179-191; M. Mancuso, The Ethical World of British Mps, McGill-Queen University Press, 1995.

24 Mancuso found that four scenarios were unanimously regarded as corrupt, that British MPs had relatively low tolerance for corruption and misconduct scenarios (tolerance level being measured on the basis of the average response provided by the $100 \mathrm{MPs}$ included in the survey) and that British MPs used their ethical standards in very consistently. Pelizzo and Ang in their comparative study of ethical standards in the UK and Indonesia showed that there are some similarities as well as some differences between the countries. In both countries, ethical standards are heterogeneous and in both countries tolerance for corruption is relatively low-though tolerance levels are slightly lower in Indonesia than they are in the UK. More importantly, they noted that in contrast to British MPs, Indonesian MPs do not apply their ethical standards in a consistent fashion. See R. Pelizzo and B. Ang, Pelizzo, Riccardo and Bernice Ang, 'An Ethical Map of Indonesian MPs', paper prepared for presentation at the 103rd Annual Meeting of the American Political Science Association, Chicago, 31 August-2 September, 2007.

25 As a point of comparison, one could observe that hiring relatives to serve as personal secretaries is a fairly common practice among Italian members of the European Parliament.

26 R. Pelizzo and S.Babones, 'The Political Economy of Polarization: The Italian Case 1963-1987', Politics and Policy, 31 (1), 2003, 54-78; R. Pelizzo and S. Babones, 'The Political Economy of Polarized Pluralism', Party Politics, 13, (1), 2007, 53-67.

27 This means that if party positions are estimated on a 7-point scale and the two relevant parties occupy positions 2 and 4 , the distance is $4-2=2$. While in a party system where the two parties occupy the positions 1 , the distance is $7-1=6$. The second party system is more polarised than the first one.

28 G. Sartori, Parties and Party Systems, Cambridge UP, 1976, p. 135.

29 M. Taylor and V. Herman, 'Party Systems and Government Stability', American Political Science Review, 65, (1), 1971, 28-37.

30 It is easier to grasp the idea that, for example, voters with extreme views greatly exceed in percent terms the voters with a neutral stance than appreciating that the standard deviation on a seven point scale is, say, 1.92 .

31 A. Wildavsky, 'Choosing Preferences by Constructing Institutions: A Cultural Theory of Preference Formation', American Political Science Review, 81, (1), 1987; 3-22, D. Braman, D. Kahan and J. Grimmelmann, 'Modeling Facts, Culture and Cognition in the Gun Debate', Social Justice Research, 18, (3), 2005, 283-304.

32 M. Douglas, Mary and A. Wildavski, Risk and Culture, University of California Press, 1982.

33 The first view is advocated by M. Verweij and M. Thompson, Clumsy Solutions in a Complex World: Governance, Politics and Plural perspectives, Palgrave, 2006; M. Verweij, 'Four Wrongs Can Make a Right', Politics \& Policy, 35, (3), 2007, 464-495. The second view is proposed by D. Braman, D. Kaman and J. Grimmelmann, "Modeling Facts, Culture and Cognition in the Gun Debate", cit., pp. 283-304.

34 M. Verweij, and M. Thompson, op. cit, 2006.

35 D. Braman, D. Kahan and J. Grimmelmann, 'Modeling Facts, Culture and Cognition in the Gun Debate', cit., p. 297.

36 D. Braman, D. Kahan and J. Grimmelmann, 'Modeling Facts, Culture and Cognition in the Gun Debate', cit., p. 297.

37 S. M. Lipset, 'Some Social Requisites for Democracy', American Political Science Review, 53, (1), 1959, 69-105. 